\title{
Diabetes management: optimizing roles for nurses in insulin initiation
}

\author{
This article was published in the following Dove Press journal: \\ Journal of Multidisciplinary Healthcare \\ 18 February 2011 \\ Number of times this article has been viewed
}

\author{
Bridget R Levich \\ University of California Davis Health \\ System, Sacramento, CA, USA
}

\begin{abstract}
Type 2 diabetes is a major public health concern. Screening and early diagnosis followed by prompt and aggressive treatment interventions can help control progression of diabetes and its complications. Nurses are often the first healthcare team members to interact with patients and are being called on to apply their specialized knowledge, training, and skills to educate and motivate patients with diabetes about insulin use and practical ways to achieve treatment goals. Clinical nurse specialists possess specific training and skills to provide this level of care, while staff or office-based nurses may be trained by physicians to fulfill a task-specific role. This manuscript reviews the benefits of intensive glycemic control in type 2 diabetes, therapeutic goals and guidelines, advances in insulin therapy, and contribution of nurses in overcoming barriers to insulin initiation and related aspects of diabetes care. Nurses are particularly well positioned to fill the gap and improve efficiency in diabetes-related healthcare by assisting patients with insulin initiation and other aspects of glycemic self-management.
\end{abstract}

Keywords: insulin, diabetes, diabetes educator, hypoglycemia, diabetes counseling, insulin clinic, insulin pens

\section{Introduction}

Diabetes is a public health matter of grave concern associated with serious longterm consequences and escalating healthcare costs, with an ever-rising incidence ( $~ 90 \%$ between 1997 and 2007) and prevalence (from 4.8 to 9.1 per 1000 population in the US). ${ }^{1}$ With such alarming statistics, the role of nurses in helping patients to control type 2 diabetes-associated morbidity and mortality is becoming increasingly important. Nurses, on the front lines, can screen patients for early diabetes identification, recognize and initiate corrective measures for inadequate treatment regimens, help patients set and achieve therapeutic goals, and assess diabetes-related complications as they arise. In so doing, they can assume an active role in educating patients about the progressive nature of type 2 diabetes and the importance of early, intensive therapy. ${ }^{2}$

Based on a preponderance of evidence from a number of landmark studies (summarized in Table $1^{3-17}$ and illustrated in Figure $1^{4}$ ), intensive treatment to achieve optimal glycemic control is associated with a lower incidence of cardiovascular and microvascular complications. ${ }^{18}$

Professional diabetes organizations, such as the American Diabetes Association (ADA), the American Association of Clinical Endocrinologists (AACE), and the European Association for the Study of Diabetes (EASD), have set aggressive goals in their guidelines for glycemic control (Table 2). ${ }^{14,15,17,19}$ Because an estimated 2 out of 3 people fail to meet the AACE target hemoglobin $\mathrm{A}_{1 \mathrm{C}}\left(\mathrm{HbA}_{1 \mathrm{C}}\right)$ goal of $6.5 \%$ 
Table I Selected major evidence and rationale for intensive diabetes management

\section{Study}

- The UKPDS (United Kingdom Prospective Diabetes Study) found that poor glycemic control in patients with type 2 diabetes is associated with an increased risk of cardiovascular complications, including coronary heart disease, myocardial infarction, and peripheral vascular disease, as well as microvascular complications and death. ${ }^{3}$ Figure I shows the relationship of hemoglobin $\mathrm{A}_{\mathrm{IC}}\left(\mathrm{Hb}_{\mathrm{IC}}\right)$ to diabetes-related complications. ${ }^{4}$

- The DCCT (Diabetes Control and Complications Trial) reported that maintaining fasting plasma glucose (FPG) between 70 and $120 \mathrm{mg} / \mathrm{dL}$ (3.89-6.67 mmol/L) and postprandial glucose (PPG) $<180 \mathrm{mg} / \mathrm{dL}$ ( $10 \mathrm{mmol} / \mathrm{L}$ ) helps sustain endogenous insulin secretion. ${ }^{5}$ Residual beta-cell function, in turn, is associated with better metabolic control and a lower risk of hypoglycemia and chronic complications, such as retinopathy and microalbuminuria. ${ }^{6}$

- The EDIC (Epidemiology of Diabetes Interventions and Complications) study found that early glycemic control reduces the risk of cardiovascular events.

- The ARIC (Atherosclerosis Risk in Communities) study reported that elevated $\mathrm{HbA}_{\mathrm{IC}}$ leads to atherosclerosis and cardiovascular disease.,

- The Steno-2 study found that intensive, multifactorial intervention reduced diabetes-related mortality and cardiovascular events..$^{10}$

- The ADVANCE (Action in Diabetes and Vascular Disease) study found that intensive glucose control reduced major macrovascular and microvascular events, primarily due to a $21 \%$ reduction in nephropathy."

- Li et al $\mathrm{a}^{4,12}$ reported that short-term intensive insulin therapy titrated to maintain FPG $<110 \mathrm{mg} / \mathrm{dL}(6.11 \mathrm{mmol} / \mathrm{L})$ and PPG $<160 \mathrm{mg} / \mathrm{dL}$ $(8.89 \mathrm{mmol} / \mathrm{L})$ prevented progression of beta-cell dysfunction and insulin resistance in newly diagnosed type 2 diabetic patients with severe hyperglycemia.

-Weng et $\mathrm{a}^{3,13-17}$ found that hyperglycemia is brought under control more quickly, and the effects of insulin on beta-cell function are superior to those of oral hypoglycemic agents.

or less, ${ }^{20}$ diabetes management can benefit from a deeper, more direct involvement by nurses. The purpose of this manuscript is to review the benefits of intensive glycemic control in type 2 diabetes, therapeutic goals and guidelines, advances in insulin therapy, and contribution of nurses in overcoming barriers to insulin initiation and related aspects of diabetes care.

\section{Early initiation of insulin to improve diabetes management}

Beta-cell dysfunction and insulin resistance are the main physiological defects responsible for the development of hyperglycemia. Chronically elevated blood glucose further compromises beta-cell function, eventually leading to a complete shutdown of insulin production. In the early stages of type 2 diabetes, patients may be able to control hyperglycemia with oral antidiabetic drug (OAD) therapy. However, the progressive nature of type 2

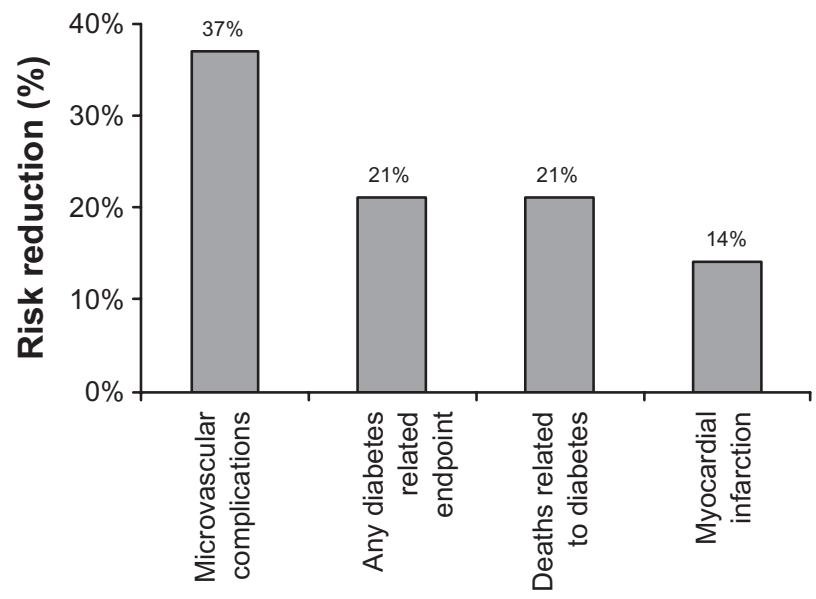

Figure I Relationship of hemoglobin $A_{I C}\left(H_{b A}\right)$ and incidence of diabetes complications. ${ }^{4}$ In the United Kingdom Prospective Diabetes Study (UKPDS), each percentage point reduction in $\mathrm{HbA}_{\mathrm{IC}}$ was linked with substantial risk reductions in diabetes-related morbidity and mortality.

diabetes will require that most patients eventually switch to combination therapy that includes insulin or convert completely to insulin..$^{21,22}$ Used in adequate doses, insulin is the most effective diabetes medication, because it can decrease any elevated level of $\mathrm{HbA}_{1 \mathrm{C}}$ to, or very close to, the therapeutic goal. ${ }^{14}$

Consensus guidelines from the ADA/EASD advocate insulin as the second step after failure on metformin monotherapy to achieve an $\mathrm{HbA}_{1 \mathrm{C}} \leq 7 \%$. ${ }^{14}$ This applies to patients who are symptomatic or have $\mathrm{HbA}_{1 \mathrm{C}}>8.5 \%$. For patients without symptoms or with $\mathrm{HbA}_{1 \mathrm{C}}$ levels that are better controlled, adding a sulfonylurea may be an appropriate second step. In treated patients whose $\mathrm{HbA}_{1 \mathrm{C}}$ remains $>7.0 \%$, insulin therapy should be initiated or the dose titrated upward. For patients with an initial $\mathrm{HbA}_{1 \mathrm{C}}>10 \%$, insulin is recommended as first-line therapy. Table 3 summarizes the main differences between oral therapies, some newer therapies for diabetes management (ie, incretin-based therapies), insulin

Table 2 Therapeutic goals for FPG, PPG, and $\mathrm{HbA}_{\mathrm{IC}}$

\begin{tabular}{llll}
\hline & FPG & 2-h PPG & HbA IC \\
\hline ADA $^{19}$ & $90-130 \mathrm{mg} / \mathrm{dL}$ & $<180 \mathrm{mg} / \mathrm{dL}$ & $<7 \%$ \\
& $(5-7.22 \mathrm{mmol} / \mathrm{L})$ & $(10 \mathrm{mmol} / \mathrm{L})$ & \\
IDF $^{17}$ & $<110 \mathrm{mg} / \mathrm{dL}$ & $<145 \mathrm{mg} / \mathrm{dL}$ & $<6.5 \%$ \\
& $(6.11 \mathrm{mmol} / \mathrm{L})$ & $(8.06 \mathrm{mmol} / \mathrm{L})$ & \\
ADA/EASD $_{\text {Consensus }}{ }^{44}$ & $70-130 \mathrm{mg} / \mathrm{dL}$ & $<180 \mathrm{mg} / \mathrm{dL}$ & $<7 \%$ \\
AACE $^{15}$ & $(3.89-7.22 \mathrm{mmol} / \mathrm{L})$ & $(10 \mathrm{mmol} / \mathrm{L})$ & \\
& $<100 \mathrm{mg} / \mathrm{dL}$ & $<140 \mathrm{mg} / \mathrm{dL}$ & $\leq 6.5 \%$ \\
& $(5.56 \mathrm{mmol} / \mathrm{L})$ & $(7.78 \mathrm{mmol} / \mathrm{L})$ & \\
\hline
\end{tabular}

Abbreviations: FPG, fasting plasma glucose; PPG, postprandial glucose; $\mathrm{HbA}_{\mathrm{IC}}$, hemoglobin $A_{I C}$; ADA, American Diabetes Association; IDF, International Diabetes Federation, EASD, European Association for the Study of Diabetes; AACE, American Association of Clinical Endocrinologists. 
Table 3 Differentiating available diabetes therapies ${ }^{14,15,23-28}$

\begin{tabular}{|c|c|c|}
\hline Antidiabetic agent & Advantages & Disadvantages \\
\hline Metformin & Weight neutral, inexpensive, oral & GI side effects, rare lactic acidosis \\
\hline Thiazolidinediones & Improved lipid profile, oral & $\begin{array}{l}\text { Fluid retention, weight gain, CHF, } \\
\text { may not see reduction in glucose for } \\
\text { several weeks, expensive, increased } \\
\text { cardiovascular risk }\end{array}$ \\
\hline Alpha-glucosidase inhibitors & Weight neutral, oral & $\begin{array}{l}\text { Frequent GI side effects, } 3 \text { times/day } \\
\text { dosing, expensive }\end{array}$ \\
\hline Sulfonylureas & Inexpensive, oral & Weight gain, hypoglycemia \\
\hline Glinides & Short duration & $\begin{array}{l}\text { Hypoglycemia, } 3 \text { times/day dosing, } \\
\text { expensive }\end{array}$ \\
\hline $\begin{array}{l}\text { DPP-4 inhibitors } \\
\text { - Saxagliptin } \\
\text { - Sitagliptin }\end{array}$ & Weight neutral, less hypoglycemia, oral & $\begin{array}{l}\text { Lack of long-term data regarding } \\
\text { safety and efficacy }\end{array}$ \\
\hline $\begin{array}{l}\text { GLP-I agonists } \\
\text { - Exenatide } \\
\text { - Liraglutide }\end{array}$ & Less hypoglycemia, weight loss & $\begin{array}{l}\text { Injections, lack of long-term data on } \\
\text { safety and efficacy }\end{array}$ \\
\hline Insulin & $\begin{array}{l}\text { Inexpensive, no dose limit, } \\
\text { improved lipid profile }\end{array}$ & $\begin{array}{l}\text { Injections, monitoring, hypoglycemia, } \\
\text { weight gain }\end{array}$ \\
\hline $\begin{array}{l}\text { Human insulin } \\
\text { - Regular or short acting } \\
\text { - Intermediate acting (NPH) }\end{array}$ & $\begin{array}{l}\text { Many physicians still most comfortable } \\
\text { with standard insulin therapy }\end{array}$ & $\begin{array}{l}\text { Limited pharmacokinetic/ } \\
\text { pharmacodynamic features, } \\
\text { hypoglycemia, injections, monitoring, } \\
\text { weight gain, variability in time-action } \\
\text { profile }\end{array}$ \\
\hline $\begin{array}{l}\text { Insulin analogs } \\
\text { - Rapid-acting analogs } \\
\circ \text { Aspart } \\
\circ \text { Lispro } \\
\circ \text { Glulisine }\end{array}$ & $\begin{array}{l}\text { Less hypoglycemia than human insulin, } \\
\text { absorption more consistent, less weight } \\
\text { gain; rapid- and long-acting formulations, } \\
\text { predictable time-action profiles, } \\
\text { simplified dosing with premixes }\end{array}$ & Injections, monitoring \\
\hline $\begin{array}{l}\text { - Long-acting basal analogs } \\
\circ \text { Glargine } \\
\circ \text { Detemir }\end{array}$ & & \\
\hline $\begin{array}{l}\text { - Premixed analogs } \\
\circ \text { Biphasic insulin aspart } 70 \\
\circ \text { Insulin lispro } 75 / 25 \\
\circ \text { Insulin lispro 50/50 }\end{array}$ & & \\
\hline \multicolumn{3}{|l|}{ Devices for insulin delivery } \\
\hline - Traditional vial and syringe & $\begin{array}{l}\text { Some physicians most comfortable with } \\
\text { standard vial and syringe insulin therapy }\end{array}$ & $\begin{array}{l}\text { Can be complicated to administer, } \\
\text { not discreet, time consuming, and } \\
\text { potential for dosing errors; patients } \\
\text { may have needle aversion }\end{array}$ \\
\hline - Pen-injection devices & $\begin{array}{l}\text { Convenient, discreet, simple, may improve } \\
\text { confidence/adherence and reduce } \\
\text { insulin-related adverse events, good } \\
\text { for patients who have vision or dexterity } \\
\text { problems, decreased dosing errors } \\
\text { and more accurate dosing }\end{array}$ & $\begin{array}{l}\text { Some patients are averse to } \\
\text { injections in any form }\end{array}$ \\
\hline
\end{tabular}

Abbreviations: Gl, gastrointestinal; CHF, congestive heart failure; DPP-4, dipeptidyl peptidase-4; GLP-I, glucagon-like peptide I; NPH, neutral protamine Hagedorn.

formulations, and convenient injection devices for insulin delivery. ${ }^{14,15,23-28}$ Approaches to insulin initiation should be customized to the patients' needs. Table 4 provides an

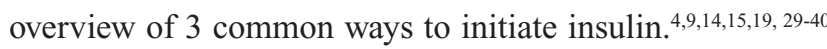
Specific dosing information depends on the method used, and the prescribing information should be consulted for the particular insulin products that are chosen and individualized for the patient.

\section{Flexibility in diabetes care and quality of life: impact of insulin analogs and pens}

Patients' concerns about flexibility and lifestyle, such as misperceptions about timing of meals and the need to carry insulin vials, needles, and syringes, can be major barriers to insulin initiation. Nurses can intervene and help patients identify and transition to therapies that are flexible, simple, 
Table 4 Insulin initiation strategies

The AACE notes that insulin can be initiated by addition to any and all oral antidiabetic drug (OAD) therapies, as long as appropriate blood glucose monitoring is performed. Several different approaches are possible: I) add a basal insulin, ${ }^{29,30} 2$ ) add a premixed insulin, ${ }^{31}$ or 3 ) add rapid-acting insulin boluses at mealtimes. ${ }^{9,32,33}$ The specific approach and insulin doses will depend on individual patients' needs, preferences, $\mathrm{HbA}_{\mathrm{IC}}$ levels, and fasting plasma glucose (FPG) levels.

\section{Initiation with basal insulin}

- Basal initiation therapy aims to normalize fasting blood glucose and $\mathrm{HbA}_{\mathrm{IC}}$. Metformin is the preferred first-line OAD for patients with type 2 diabetes but can be expected to reduce $\mathrm{HbA}_{\mathrm{IC}}$ values by only $\sim 1.5 \%$. $^{14,34,35}$

- To achieve target $\mathrm{HbA}_{\mathrm{IC}}$ goals, basal insulin is added to metformin, typically at a dose of 10 units/day.

- Adjustment of the daily dose will depend on the FPG and on the basal insulin selected. ${ }^{36,37}$

- Two long-acting basal insulin analogs, insulin detemir and glargine, have pharmacodynamic profiles that provide up to 24-hour basal insulin levels, generally with a once-daily injection at bedtime.

- Because type 2 diabetes is a progressive disease, most patients will ultimately require the addition of rapid-acting bolus insulin injections at mealtimes to control postprandial glucose (PPG) (see below).

- A basal-bolus regimen is ideal for many patients, as it mimics the body's constant release of insulin throughout the day and supplements the body's need for insulin after a meal.

\section{Premixed insulins}

- Premixed insulins are formulated to combine both basal and rapidacting components in I injection and thus provide a simple way to achieve near-normal insulin profiles at mealtime and between meals.

- Premixed insulins are easy to use, ensure that the correct amount of insulin is injected every time, and may improve adherence to therapy. They are especially helpful for patients who are older, averse to multiple injections, or prefer a simple insulin regimen.

- Premixed insulins are given in once-, twice-, or 3-times daily schedules, depending on the patient's needs.

-When initiating a premixed insulin, metformin should be continued, but if the patient is currently taking a secretagogue, it should be discontinued.

- Individuals who eat regular meals on a schedule are ideally suited for premixed insulins; however, premixes are not a preferred option for patients with varied daily schedules or those who require flexibility around mealtimes.

- Specific dosing and titration information depend on the formulation chosen.

\section{Rapid, short-acting insulin injections at mealtime}

- Tight control over PPG excursions can be exerted using mealtime bolus insulin injections.

- As beta-cell function declines with disease progression, prandial insulin injections will eventually be required by most patients with type 2 diabetes.

- Controlling PPG levels so they remain below 140 to $180 \mathrm{mg} / \mathrm{dL}$ $(7.78-10 \mathrm{mmol} / \mathrm{L})^{19}$ is important to delay the onset of vascular damage, ${ }^{4,39}$ and contributes to achievement of overall $\mathrm{HbA}_{\mathrm{IC}}$ goals. ${ }^{14,40}$

- Adding a bolus injection of a rapid-acting mealtime insulin analog (lispro, aspart, or glulisine) is ideally suited for patients who require flexibility, since it may be given immediately before or even during a meal, ie, "inject and eat" rather than waiting 15 to 30 minutes with regular insulin. The dose can be varied based on the patient's glucose levels or the size/type of meal. This approach is supported by AACE medical guidelines. ${ }^{15}$ convenient, and well suited to their patients' lifestyles so adherence and quality of life are maximized.

Older human insulin formulations ( $\mathrm{eg}$, neutral protamine Hagedorn $[\mathrm{NPH}]$ and regular insulin) are characterized by unpredictable pharmacokinetic and pharmacodynamic time-action profiles that produce variable effects. When the physiological or normal pattern of insulin response to food intake is not reproduced, hypoglycemia and weight gain can occur. ${ }^{41,42}$ These undesirable effects, in turn, result in a low degree of satisfaction and poor therapy adherence. Fortunately, the choices of insulin formulations and delivery systems have expanded considerably in the last decade..$^{23,43}$ Insulin analogs were specifically designed to mimic the body's physiological insulin response (Figure 2). ${ }^{44}$

The long-acting insulin analogs (glargine and detemir) have important advantages over NPH. Due to their protracted duration of action, they can be administered as once-daily injections. The lack of a distinct peak in insulin activity and less variability in plasma insulin levels after injection are believed to account for the lower risk of hypoglycemia, particularly at night, when there is a long delay between meals. ${ }^{43,45}$ Despite having similar efficacy in terms of lowering $\mathrm{HbA}_{1 \mathrm{C}}$ and fasting plasma glucose (FPG), most studies show a $22 \%$ to $47 \%$ lower risk of nocturnal hypoglycemia and $25 \%$ to $34 \%$ lower risk of severe hypoglycemia with insulin analogs compared with NPH. ${ }^{43,46,47}$ For patients whose concern is additional weight gain when initiating insulin, detemir is a good choice; it has been shown to cause 1.4 to $1.6 \mathrm{~kg}$ less weight gain, on average, than $\mathrm{NPH}^{48,49}$ In one study, patients with type 2 diabetes with a higher baseline body mass index $\left(>35 \mathrm{~kg} / \mathrm{m}^{2}\right)$ who received detemir lost an average of $0.5 \mathrm{~kg}$ compared with those receiving $\mathrm{NPH}$, who gained an average of $2.4 \mathrm{~kg}$, at equivalent levels of glycemic control. ${ }^{49}$ Patients

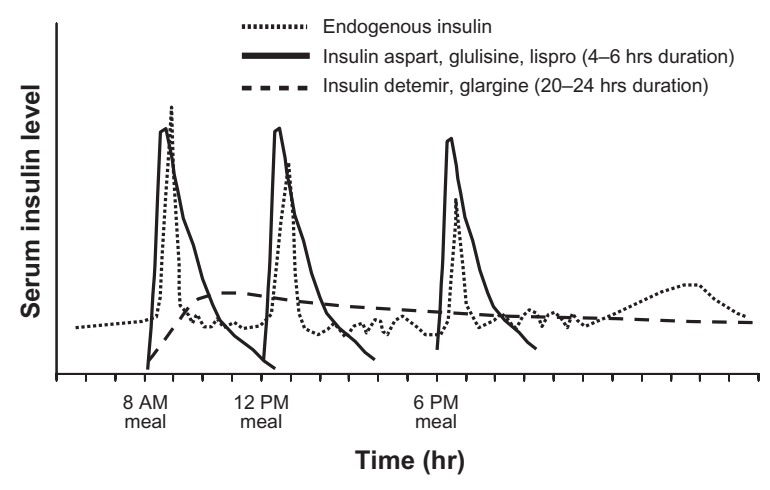

Figure 2 Approximate pharmacokinetic profiles of rapid- and long-acting insulin analogs as compared with an idealized profile of physiological insulin secretion. ${ }^{44}$

Copyright (c) 2007 [Lippincott, Williams \& Wilkins] Reprinted with permission from Boyle PJ, Zrebiec J. Management of diabetes-related hypoglycemia. South Med J. 2007; 100(2):183-194.44 
with type 2 diabetes participating in a treat-to-target study with a basal-bolus insulin regimen gained significantly less weight $(1.2 \pm 4 \mathrm{~kg})$ when treated with detemir compared with glargine $(2.7 \pm 4 \mathrm{~kg} ; P=0.001)$ after 26 weeks, despite achieving similar reductions in $\mathrm{HbA}_{1 \mathrm{C}}(1.1 \%$ vs $1.3 \%$, respectively) and with similar hypoglycemia incidence. ${ }^{50}$ The lack of weight gain observed with long-acting detemir compared with NPH and glargine makes it ideally suited for patients with type 2 diabetes who tend to be overweight and for whom weight gain could present additional health risks.

The rapid-acting insulin analogs (lispro, aspart, and glulisine) have improved time-action profiles that also offer several advantages over fast-acting regular insulin. These advantages include better efficacy in lowering postprandial glucose (PPG), increased safety due to a lower risk of late postprandial hypoglycemia, less blood glucose variability, and greater flexibility around mealtime dosing and timing of injections. ${ }^{43}$ Because the onset of action is between 5 and 15 minutes compared with 30 to 60 minutes for regular insulin, ${ }^{23}$ the rapid-acting analogs can be injected immediately before, or even after, the meal has begun. This mealtime flexibility can have a positive impact on quality of life and promote satisfaction and adherence to therapy. ${ }^{51}$

Premixed insulin analogs, containing both a long-acting and a rapid-acting formulation, can offer even more simplicity and convenience for patients and provide excellent glycemic control, although sometimes at the expense of additional hypoglycemia and weight gain. Three premixed insulin analogs (biphasic insulin aspart 70/30, insulin lispro 75/25, and insulin lispro 50/50) are available in the US and come in easy-to-use pen devices. ${ }^{27}$ Patients in a study of premixed insulin achieved lower $\mathrm{HbA}_{1 \mathrm{C}}$ levels than with once-daily basal insulin (7.1\% vs $7.7 \%$, respectively; $P<0.001)$ with a similar low occurrence of hypoglycemia events $(0.8$ vs 0.5 per person per month, respectively). ${ }^{52} \mathrm{~A}$ comprehensive review comparing premixed insulins to basal insulin noted that twice-daily administration of a premixed insulin decreased $\mathrm{HbA}_{1 \mathrm{C}}$ between $1 \%$ and $2.7 \%$ compared with $0.4 \%$ to $2.4 \%$ with basal insulin analogs $(P<0.01)$, with slightly higher overall hypoglycemia and similar nocturnal or severe hypoglycemia. ${ }^{53}$

Use of a vial with a syringe can be difficult and cumbersome, particularly for patients with diabetes-related visual disturbances, dexterity issues, or physical impairments. Today, the more patient-friendly insulin pens prefilled with insulin analogs are discreet and convenient and may help patients overcome social embarrassment associated with selfinjection, leading to increased adherence..$^{27,28}$ These devices are also equipped with smaller, less intimidating needles that have a thinner gauge than conventional needles and may help dispel needle anxiety. ${ }^{54}$ According to a review about confidence and convenience in insulin delivery systems, ${ }^{27}$ administering insulin with prefilled pen devices compared with traditional vials and syringes allows for improved adherence, fewer hypoglycemic events, reduced emergency department and physician visits, better quality of life, more accurate dosing, and lower annual treatment costs, thereby reducing many of the barriers associated with insulin use.

Nurses have reported a high level of patient satisfaction with pens. In an 11-month satisfaction survey, the majority $(69 \%)$ of nurses found pens to be an improvement in insulin administration over the conventional method based on convenience, simplicity and ease of use, and time to prepare and administer the insulin dose. Approximately $44 \%$ of nurses also reported that it took less than 15 minutes to instruct patients on the use of pens, while $28 \%$ of nurses reported needing 15 minutes or less to instruct patients on the use of conventional vials and syringes. ${ }^{55}$

\section{Implementing a patient-driven insulin titration algorithm}

Once insulin is initiated, a simple, patient-driven insulin titration algorithm can be taught that empowers patients to take active control of their own diabetes management. After careful assessment of patient comfort level as well as ability to comprehend and demonstrate the information back correctly, patients are given a printed titration tool in which they can log bedtime and fasting glucose levels and make small dose titrations accordingly. This practice can increase the rate at which glucose control is improved as well as actively involve patients in their own insulin regimens. Examples of very effective patient-directed insulin titration algorithms can be found in the literature. ${ }^{56-61}$ In a study, patients simply tested their FPG and adjusted their basal insulin doses accordingly. For an FPG $<80 \mathrm{mg} / \mathrm{dL}(4.44 \mathrm{mmol} / \mathrm{L})$, insulin was titrated down 3 units; if FPG was between $80 \mathrm{mg} / \mathrm{dL}$ and $110 \mathrm{mg} / \mathrm{dL}$ (4.44-6.11 mmol/L), the units remained unchanged; if the FPG was $>110 \mathrm{mg} / \mathrm{dL}(6.11 \mathrm{mmol} / \mathrm{dL})$, insulin was adjusted up 3 units. The glycemic control achieved in the patientdriven algorithm was equivalent to the physician-titrated insulin therapy. ${ }^{57,58}$

\section{Nurses' unique role in type 2 diabetes education and management}

Clinical nurse specialists (CNSs), specialized in diabetes and trained to understand the behavioral aspects of living with 
chronic illness, are especially well positioned to provide the patient education and coaching necessary to promote diabetes self-management. ${ }^{34,62}$

\section{Motivational interviewing}

Motivational interviewing is a patient-centered, passive counseling style that can be used to encourage patients to resolve their own health-related concerns. ${ }^{63-65} \mathrm{It}$ is an ideal approach for identifying reasons why patients are hesitant to initiate insulin. Nurses pose questions that are directive, designed to elicit the patients' perceptions about the advantages and disadvantages of insulin therapy, or what motivates patients to change certain behaviors. After listening carefully to individual responses, the technique involves repeating back what the patient said without trying to persuade; instead offering acceptance and reinforcement, emphasizing freedom of choice and self-direction. ${ }^{63}$ Structured in this way, the nurse is better able to determine a patient's ability or readiness for change from the discussion.

Rollnick and Miller wrote, "Motivational interviewing is not a technique for tricking people into doing what they do not want to do. Rather, it is a skillful clinical style for eliciting from patients their own good motivations for making behavioral changes in the interest of their health. It involves guiding more than directing, dancing rather than wrestling, listening at least as much as telling. The overall 'spirit' has been described as collaborative, evocative, and honoring of patient autonomy". ${ }^{66}$

\section{Exploring patients' barriers to insulin use and debunking insulin myths}

Nurses can use motivational interviewing as part of the rapport-building process to explore the patient's beliefs about insulin therapy and then gently begin to reposition insulin in a positive light. Patient barriers typically fall under a number of definable categories: denial of the need for insulin; misconceptions about insulin; fear of injections, weight gain, and hypoglycemia; and complexities of insulin use. By following a systematic approach, patient obstacles can be identified, clarified, and overcome. Some common scenarios relating to barriers and strategies to address and overcome them are:

- Ask patients if they understand that most patients with type 2 diabetes eventually require insulin, and then reinforce the idea that insulin, when initiated promptly, can help delay further progression of the disease.

- Convey that initiation of insulin is a well-established treatment strategy. The need for insulin does not reflect a failure on the patient's part but a natural progression of the disease. This should help correct the misconception that the diabetes must be very severe if they need insulin and should help clear the air about denial or fear.

- Provide information about national guidelines and explain that the guidelines are based on landmark studies and years of research. Patients will appreciate learning about these studies from a nurse and will likely feel more confident and empowered about their disease (Table 1).

- Identify and dispel any misconceptions about insulin therapy causing complications such as renal failure or blindness. Explain that these complications may actually be prevented if insulin is initiated earlier.

- Listen to the patient's specific concerns about weight gain and hypoglycemia with insulin therapy. In this case, the nurse's knowledge of insulin analogs becomes an important part of patient education. Use the opportunity to introduce the patient to new technologies, explaining that the insulin analogs were specifically designed to mimic normal physiology and that they pose a lower risk of these unwanted effects, while providing an effective means of controlling hyperglycemia.

- Teach patients about the symptoms of hypoglycemia and how to recognize and self-treat (Table 5). 4,44,67,68 Patients' concerns about hypoglycemia should also prompt a refocus of the discussion on nutrition. Explain to patients that they may feel less hungry as blood glucose improves.

- Instruct patients with needle anxiety about new technologies, including pen devices and fine-coated needles, to make them more comfortable. ${ }^{26,69,70}$ For patients who still express injection anxiety, have them self-administer the first injection in your presence. If the timing is not appropriate while in the clinic/office for an insulin dose, encourage injection of 5 "units" of saline. Most often, the patient's response is “That's it? I didn't even feel it!" Anxiety about self-injection at home will be significantly reduced. ${ }^{27,28}$

- Discuss the differences in needle gauges for patients who express concern about injection pain and show them the subcutaneous needle size. Demonstrate how an insulin pen device works compared with the traditional vial and syringe to emphasize its convenience, small needle size, and ease of use. ${ }^{69,70}$ Do the same with blood glucose-monitoring devices.

- Address concerns about the complexities of an insulin regimen by discussing premixed insulins or teach a simple patient-directed algorithm (refer to the earlier section on patient-driven insulin titration algorithms). Insulin pen devices also greatly simplify insulin administration. Talk about the flexibility around mealtime and that 
Table 5 Symptoms and management of hypoglycemia

Hypoglycemia symptoms can vary considerably from patient to patient. ${ }^{44}$

Common symptoms

- Pallor

- Sweating

- Increased heart rate

- Feelings of shakiness

- Blurred vision

- Tingling sensation

- Difficulty concentrating

- Feeling weak

- Tiredness or clumsiness

- Feeling warm or cold

- Feeling hungry

- Changes in mood (manifesting as giddiness, anger or irritability, anxiety or frustration, or tearfulness)

- Seizures or loss of consciousness (if the hypoglycemia is very severe) ${ }^{44}$

Management

Mild-to-moderate

- Fast-acting carbohydrates (glucose tablets, fruit juices, drinks high in sugar content, or glucose gels).

- Five grams of carbohydrate raises plasma glucose by $\sim 15 \mathrm{mg} / \mathrm{dL}$ ( $0.83 \mathrm{mmol} / \mathrm{L})$. A typical hypoglycemic episode is treated by ingesting $15 \mathrm{~g}$ of carbohydrate. $4,67,68$

- If, after 15 minutes, plasma glucose remains $<70 \mathrm{mg} / \mathrm{dL}$ ( $3.89 \mathrm{mmol} / \mathrm{L})$, another carbohydrate-rich snack should be ingested (the I5/I5 rule). Glucose gels are absorbed by the buccal mucosa and can be administered by an attendant in the event the patient is not alert. This may be followed by juice or food once the patient is more alert.

Severe

- Very severe hypoglycemia might require intravenous administration of glucose by trained medical personnel.

- In cases of severe or frequent hypoglycemia or hypoglycemic unawareness, it is prudent to instruct the patient and significant other(s) in the use of glucagon, an injectable treatment for hypoglycemia in the unconscious patient.

the rapid-acting insulin analogs make it possible to "inject-and-eat".

- Reinforce the patient's role as an active decision maker in his/her own treatment, while offering information, direction, and support. ${ }^{14,34}$

\section{Insulin therapy evaluation clinics: a new paradigm for diabetes education and care by the CNS}

Educational interventions organized and executed by nurses and centered on patient self-management are effective. ${ }^{71}$ Nurses and physicians agree that nurses should play a larger role in managing diabetes. ${ }^{2}$ The CNS, with advanced practice skills in adult diabetes education, is ideally suited to take this on. CNSs are not often called on to see patients individually for insulin therapy evaluation; however it is an appropriate use of the skills of this level of nurse. Office staff nurses are less well suited for this role, as their focus is on acute care or individual physician support. The DAWN study suggested that, compared with primary care providers (PCPs), nurses tended to provide better education, spent more time with patients, were better listeners, and knew their patients better. ${ }^{34}$ By taking the role of a diabetes educator as well as a care provider, an advanced practice nurse such as the CNS will improve patient-provider communication. ${ }^{19}$ Given adequate training and time with patients, advanced practice nurses will be able to play an increasingly important role in initiation and management of insulin therapy. ${ }^{34}$ As an example of the CNS involvement in diabetes management, patients are beginning to be referred by physicians to insulin therapy evaluation (ITE) or "insulin start" clinics run by CNSs. Such clinics fulfill a variety of patient needs; most common reasons for patient referrals by PCPs are listed in Table 6 .

At the University of California Davis Health System (UCDHS), ITE clinics are conducted at several of the primary care network clinics. CNSs work with patient referrals from PCPs and see patients in 45-minute increments. Whereas the PCP referral sometimes indicates a specific regimen to initiate, more often, the CNS is asked to assess the patient and make recommendations for initiating insulin therapy. It is not uncommon to see patients on basal-bolus insulin who are still not optimally controlled, as evidenced by their $\mathrm{HbA}_{1 \mathrm{C}}$. These patients will receive counseling on carbohydrate-toinsulin ratios, nutritional challenges, or how to adjust insulin bolus doses, based on blood glucose levels using correction factors. The use of insulin-delivery devices and blood glucose monitors are reviewed for all patients because problems with patient techniques, calculations, and injection practices are frequently encountered. Following each patient session, nursing notes are entered into the electronic medical record

Table 6 Reasons for patient referral to insulin therapy evaluation clinics

- Initiation of insulin for patients who are poorly controlled on OAD therapies

- Insulin dose adjustments for patients who are not achieving $\mathrm{HbA}_{\mathrm{IC}}$ goals with basal-bolus therapy

- Instruction on self-titration tools for basal insulin

- Instruction on carbohydrate counting and carbohydrate-to-insulin ratios

- Evaluation of patients' ability to self inject (includes pen-vs-syringe demonstrations)

- General education about the role of insulin in diabetes management

- Instruction on the use of self-monitoring blood glucose monitors

- Hypoglycemia prevention and management 
and the PCP cosigns the chart and any insulin or supply orders. Currently, UCDHS is considering a shared appointment model in which multiple patients with insulin referrals are seen as a group. This idea stems from the Chronic Care Model (Table 7) 72 $^{2}$ initiative and is expected to be a costeffective approach.

On a smaller scale, the ITE concept can be adapted to an office setting. Development of an office-based nurse insulin initiation team would provide patients with more one-on-one nurse instruction and coaching. Diabetes education protocols can be developed to guide nurses through all the steps necessary to educate and empower patients to participate in self-management. The office-based nurse could function in a task-focused manner, providing support for the physician or the CNS in a supervised office setting.

\section{Develop and participate in follow-up treatment plans}

In addition to managing immediate needs for glucose control $\left(\mathrm{HbA}_{1 \mathrm{C}}, \mathrm{FPG}\right.$, and PPG), nurse-run education and follow-up care is necessary to help patients maintain control of their diabetes over the long term. Actionable items include the following:2,14,19,34

- Encourage patients to maintain recommended levels of blood glucose, blood pressure, microalbumin, and cholesterol through diligent adherence to therapy.

- Promote lifestyle changes, such as meal planning and mild-to-moderate exercise.

- Establish a schedule for timely routine screenings for diabetes-related complications.

- Advocate patient participation in weekly diabetes selfmanagement classes at a local ADA-recognized diabetes program.

Table 7 Self-management and the chronic care model ${ }^{72}$

Nearly half of all people with chronic illness have multiple conditions.

Insurers have an interest in correcting specific issues in chronic disease management, including:

- Practitioners who, because of high caseload, are too rushed

to consult or follow established practice guidelines

- Lack of care coordination

- Lack of active follow-up to ensure the best outcomes

- Patients inadequately trained to manage their illnesses

Notes: To overcome these issues, the Improving Chronic Illness Care organization created the Chronic Care Model, which summarizes basic elements for improving healthcare. The model draws on best practices and research findings and provides a foundation for collaborative programs, tools, and research aimed at improving care for the chronically ill (see http://www.improvingchroniccare.org for additional information and resources). ${ }^{72}$
- Empower patients with all of the information, tools, and training necessary to successfully manage their diabetes at home.

- Reinforce the importance of the patient as the key decision maker in his/her own care but emphasize that they can always rely on the guidance of the healthcare team.

- Acknowledge that bumps in the road are to be expected, the best lessons learned are those that patients figure out on their own, and self-management of chronic conditions requires ongoing behavioral monitoring.

- Stress that the goal of the entire healthcare team is for the patient to achieve overall targets and not perfection.

\section{Conclusions}

The most valuable role of the nurse as a diabetes case manager is to ensure treatment effectiveness and patient satisfaction. The care of patients with type 2 diabetes must be tailored toward individual needs, beginning with education and adoption of an optimized treatment regimen. Guidelines from national organizations, the components of patients' daily routines, and individual responses to therapy are among the many factors to consider when setting treatment goals. For patients being initiated on insulin, it is critical to understand and overcome any barriers that could impair treatment success. The insulin analogs, premixed insulin formulations, and pen-type delivery systems have improved the safety, efficacy, and satisfaction for patients with type 2 diabetes and have all but eliminated most of the common barriers to insulin therapy, including hypoglycemia, weight gain, and inconvenience. Nurses should leverage these medical advancements and empower patients to self-manage their diabetes so they may improve the quality of their daily life as well as avoid potential complications later in life.

\section{Acknowledgments}

The author wishes to thank Jodie Bender of MedVal Scientific Information Services, LLC, for providing writing and editorial assistance. This manuscript was prepared according to the International Society for Medical Publication Professionals' Good Publication Practice for Communicating CompanySponsored Medical Research: the GPP2 Guidelines. Funding to support the preparation of this manuscript was provided by Novo Nordisk Inc.

\section{Disclosure}

The author has no real or apparent conflicts of interest due to affiliation with any company or manufacturer whose products are mentioned in the article. 


\section{References}

1. Kirtland KA, Li YF, Geiss LS, Thompson TJ. State-specific incidence of diabetes among adults-participating states, 1995-1997 and 2005-2007. MMWR Morb Mortal Wkly Rep. 2008;57(43):1169-1173.

2. Burden M. Diabetes: treatment and complications-the nurse's role. Nurs Times. 2003;99(2):30-32.

3. UK Prospective Diabetes Study Group. Intensive blood-glucose control with sulphonylureas or insulin compared with conventional treatment and risk of complications in patients with type 2 diabetes (UKPDS 33). Lancet. 1998;352(9131):837-853.

4. Stratton IM, Adler AI, Neil HA, et al. Association of glycaemia with macrovascular and microvascular complications of type 2 diabetes (UKPDS 35): prospective observational study. BMJ. 2000;321(7258): 405-412.

5. Diabetes Control and Complications Trial Research Group. Effect of intensive therapy on residual beta-cell function in patients with type 1 diabetes in the Diabetes Control and Complications Trial. A randomized, controlled trial. Ann Intern Med. 1998;128(7):517-523.

6. Steffes MW, Sibley S, Jackson M, Thomas W. Beta-cell function and the development of diabetes-related complications in the Diabetes Control and Complications Trial. Diabetes Care. 2003;26(3):832-836.

7. DCCT/EDIC Research Group. Intensive diabetes treatment and cardiovascular disease in patients with type 1 diabetes. $N$ Engl J Med. 2005; 353(25):2643-2653.

8. Selvin E, Coresh J, Golden SH, Boland LL, Brancati FL, Steffes MW. Glycemic control, atherosclerosis, and risk factors for cardiovascular disease in individuals with diabetes: the Atherosclerosis Risk in Communities study. Diabetes Care. 2005;28(8):1965-1973.

9. Holman RR, Paul SK, Bethel MA, Matthews DR, Neil HA. 10-year follow-up of intensive glucose control in type 2 diabetes. N Engl J Med. 2008;359(15):1577-1589.

10. Gaede P, Vedel P, Parving H-H, Pedersen O. Intensified multifactorial intervention in patients with type 2 diabetes mellitus and microalbuminuria: the Steno type 2 randomised study. Lancet. 1999;353(9153): 617-622.

11. Advance Collaborative Group. Intensive blood glucose control and vascular outcomes in patients with type 2 diabetes. $N$ Engl J Med. 2008; 358(24):2560-2572.

12. Li Y, Xu W, Liao Z, et al. Induction of long-term glycemic control in newly diagnosed type 2 diabetic patients is associated with improvement of beta-cell function. Diabetes Care. 2004;27(11): 2597-2602.

13. Weng J, Li Y, Xu W, et al. Effect of intensive insulin therapy on betacell function and glycaemic control in patients with newly diagnosed type 2 diabetes: a multicentre randomised parallel-group trial. Lancet. 2008;371(9626):1753-1760.

14. Nathan DM, Buse JB, Davidson MB, et al. Medical management of hyperglycemia in type 2 diabetes: a consensus algorithm for the initiation and adjustment of therapy. A consensus statement of the American Diabetes Association and the European Association for the Study of Diabetes. Diabetes Care. 2009;32(1):193-203.

15. American Association of Clinical Endocrinologists. American Association of Clinical Endocrinologists medical guidelines for clinical practice for the management of diabetes mellitus. Endocr Pract. 2007;13(Suppl 1):4-68.

16. ACE/AACE Diabetes Road Map Task Force. Road map for the prevention and treatment of type 2 diabetes. Endocr Pract. 2006;12(Suppl 1): $148-151$

17. IDF Clinical Guidelines Task Force. Global guideline for type 2 diabetes. Brussels: International Diabetes Federation; 2005:1-79.

18. Mannucci E, Monami M, Lamanna C, Gori F, Marchionni N. Prevention of cardiovascular disease through glycemic control in type 2 diabetes: a meta-analysis of randomized clinical trials. Nutr Metab Cardiovasc Dis. 2009;19(9):604-612.

19. American Diabetes Association. Standards of medical care in diabetes-2010. Diabetes Care. 2010;33(Suppl 1):S11-S61.
20. American Association of Clinical Endocrinologists. State of diabetes in America. http://www.aace.com/public/awareness/stateofdiabetes/ DiabetesAmericaReport.pdf. Accessed Nov 182010.

21. Tibaldi J, Rakel RE. Why, when and how to initiate insulin therapy in patients with type 2 diabetes. Int J Clin Pract. 2007;61(4):633-644.

22. Turner RC, Cull CA, Frighi V, Holman RR. Glycemic control with diet, sulfonylurea, metformin, or insulin in patients with type 2 diabetes mellitus: progressive requirement for multiple therapies (UKPDS 49). JAMA. 1999;281(21):2005-2012.

23. Hirsch IB. Insulin analogues. N Engl J Med. 2005;352(2):174-183.

24. Gallwitz B. Sitagliptin: profile of a novel DPP-4 inhibitor for the treatment of type 2 diabetes. Drugs Today (Barc). 2007;43(1):13-25.

25. Lebovitz HE. Therapeutic options in development for management of diabetes: pharmacologic agents and new technologies. Endocr Pract. 2006;12(Suppl 1):142-147.

26. Diabetes Forecast. 2008 Resource guide - insulin. Diabetes Forecast. 2008;61(1):RG11-RG14.

27. Korytkowski M, Niskanen L, Asakura T. FlexPen ${ }^{\circledR}$ : addressing issues of confidence and convenience in insulin delivery. Clin Ther. 2005; 27(Suppl B):S89-S100.

28. Lee WC, Balu S, Cobden D, Joshi AV, Pashos CL. Medication adherence and the associated health-economic impact among patients with type 2 diabetes mellitus converting to insulin pen therapy: an analysis of third-party managed care claims data. Clin Ther. 2006; 28(10): 1712-1725.

29. Riddle MC. Making the transition from oral to insulin therapy. $\mathrm{Am}$ J Med. 2005;118(Suppl 5A):14S-20S.

30. Boyle PJ, Zrebiec J. Physiological and behavioral aspects of glycemic control and hypoglycemia in diabetes. South Med J. 2007;100(2):175-182.

31. Rolla AR, Rakel RE. Practical approaches to insulin therapy for type 2 diabetes mellitus with premixed insulin analogues. Clin Ther. 2005; 27(8):1113-1125.

32. Levy P. Insulin analogs or premixed insulin analogs in combination with oral agents for treatment of type 2 diabetes. Med Gen Med. 2007; 9(2):12.

33. Funnell MM, Kruger DF, Spencer M. Self-management support for insulin therapy in type 2 diabetes. Diabetes Educ. 2004;30(2):274-280.

34. Siminerio LM, Funnell MM, Peyrot M, Rubin RR. US nurses' perceptions of their role in diabetes care: results of the cross-national Diabetes Attitudes Wishes and Needs (DAWN) Study. Diabetes Educ. 2007;33(1):152-162.

35. Woerle HJ, Neumann C, Zschau S, et al. Impact of fasting and postprandial glycemia on overall glycemic control in type 2 diabetes importance of postprandial glycemia to achieve target HbA1c levels. Diabetes Res Clin Pract. 2007;77(2):280-285.

36. Riddle MC, Rosenstock J, Gerich J. The treat-to-target trial: randomized addition of glargine or human NPH insulin to oral therapy of type 2 diabetic patients. Diabetes Care. 2003;26(11):3080-3086.

37. Novo Nordisk. Levemir insulin dosing options for diabetes treatment. http://www.novomedlink.com/products/Levemir/about-dosing.aspx. Accessed Nov 182010.

38. American Diabetes Association. Standards of medical care in diabetes-2009. Diabetes Care. 2009;32(Suppl 1):S13-S61.

39. Tibaldi J. Importance of postprandial glucose levels as a target for glycemic control in type 2 diabetes. South Med J. 2009;102(1):60-66.

40. Monnier L, Lapinski H, Colette C. Contributions of fasting and postprandial plasma glucose increments to the overall diurnal hyperglycemia of type 2 diabetic patients: variations with increasing levels of $\mathrm{HbA}(1 \mathrm{c})$. Diabetes Care. 2003;26(3):881-885.

41. Diabetes Control and Complications Trial Research Group. Hypoglycemia in the Diabetes Control and Complications Trial. Diabetes. 1997;46(2):271-286.

42. Diabetes Control and Complications Trial Research Group. Influence of intensive diabetes treatment on body weight and composition of adults with type 1 diabetes in the Diabetes Control and Complications Trial. Diabetes Care. 2001;24(10):1711-1721. 
43. Rossetti P, Porcellati F, Fanelli CG, Perriello G, Torlone E, Bolli GB. Superiority of insulin analogues versus human insulin in the treatment of diabetes mellitus. Arch Physiol Biochem. 2008;114(1):3-10.

44. Boyle PJ, Zrebiec J. Management of diabetes-related hypoglycemia. South Med J. 2007;100(2):183-194.

45. Brunton SA. Nocturnal hypoglycemia: answering the challenge with long-acting insulin analogs. Med Gen Med. 2007;9(2):38.

46. Singh SR, Ahmad F, Lal A, Yu C, Bai Z, Bennett H. Efficacy and safety of insulin analogues for the management of diabetes mellitus: a meta-analysis. CMAJ. 2009;180(4):385-397.

47. Gerich JE. Insulin glargine: long-acting basal insulin analog for improved metabolic control. Curr Med Res Opin. 2004;20(1):31-37.

48. Hermansen K, Davies M, Derezinski T, Ravn GM, Clauson P, Home P. A 26-week, randomized, parallel, treat-to-target trial comparing insulin detemir with NPH insulin as add-on therapy to oral glucose-lowering drugs in insulin-naive people with type 2 diabetes. Diabetes Care. 2006;29(6):1269-1274.

49. Raslova K, Tamer SC, Clauson P, Karl D. Insulin detemir results in less weight gain than NPH insulin when used in basal-bolus therapy for type 2 diabetes mellitus, and this advantage increases with baseline body mass index. Clin Drug Invest. 2007;27(4):279-285.

50. Raskin P, Gylvin T, Weng W, Chaykin L. Comparison of insulin detemir and insulin glargine using a basal-bolus regimen in a randomized, controlled clinical study in patients with type 2 diabetes. Diabetes Metab Res Rev. 2009;25(6):542-548.

51. Hartman I. Insulin analogs: impact on treatment success, satisfaction, quality of life, and adherence. Clin Med Res. 2008;6(2):54-67.

52. Robbins DC, Beisswenger PJ, Ceriello A, et al. Mealtime 50/50 basal + prandial insulin analogue mixture with a basal insulin analogue, both plus metformin, in the achievement of target $\mathrm{HbAlc}$ and pre- and postprandial blood glucose levels in patients with type 2 diabetes: a multinational, 24-week, randomized, open-label, parallel-group comparison. Clin Ther. 2007;29(11):2349-2364.

53. Ilag LL, Kerr L, Malone JK, Tan MH. Prandial premixed insulin analogue regimens versus basal insulin analogue regimens in the management of type 2 diabetes: an evidence-based comparison. Clin Ther. 2007;29(6P):1254-1270.

54. Brunton S. Insulin delivery systems: reducing barriers to insulin therapy and advancing diabetes mellitus treatment. Am J Med. 2008; 121(Suppl 6):S35-S41.

55. Davis EM, Bebee A, Crawford L, Destache C. Nurse satisfaction using insulin pens in hospitalized patients. Diabetes Educ. 2009;35(5): 799-809.

56. Davies M, Lavalle-Gonzalez F, Storms F, Gomis R. Initiation of insulin glargine therapy in type 2 diabetes subjects suboptimally controlled on oral antidiabetic agents: results from the AT.LANTUS trial. Diabetes Obes Metab. 2008;10(Suppl 2):42-49.

57. Selam JL, Koenen C, Weng W, Meneghini L. Improving glycemic control with insulin detemir using the 303 algorithm in insulin naive patients with type 2 diabetes: a subgroup analysis of the US PREDICTIVE 303 study. Curr Med Res Opin. 2008;24(1):11-20.
58. Greaves CJ, Brown P, Terry RT, Eiser C, Lings P, Stead JW. Converting to insulin in primary care: an exploration of the needs of practice nurses. J Adv Nurs. 2003;42(5):487-496.

59. Davies M, Sinnassamy P, Storms F, Gomis R. Insulin glargine-based therapy improves glycemic control in patients with type 2 diabetes sub-optimally controlled on premixed insulin therapies. Diabetes Res Clin Pract. 2008;79(2):368-375.

60. Blonde L, Merilainen M, Karwe V, Raskin P. Patient-directed titration for achieving glycaemic goals using a once-daily basal insulin analogue: an assessment of two different fasting plasma glucose targets - the TITRATE study. Diabetes Obes Metab. 2009;11(6):623-631.

61. Strange P. Treat-to-target insulin titration algorithms when initiating long or intermediate acting insulin in type 2 diabetes. $J$ Diabetes Sci Technol. 2007;1(4):540-548.

62. Watts SA, Gee J, O'Day ME, et al. Nurse practitioner-led multidisciplinary teams to improve chronic illness care: the unique strengths of nurse practitioners applied to shared medical appointments/group visits. J Am Acad Nurse Pract. 2009;21(3):167-172.

63. Rollnick S, Miller W. What is motivational interviewing? Behav Cogn Psychother. 1995;23:325-334.

64. Resnicow K, DiIorio C, Soet JE, Ernst D, Borrelli B, Hecht J. Motivational interviewing in health promotion: it sounds like something is changing. Health Psychol. 2002;21(5):444-451.

65. Clark M, Hampson SE. Implementing a psychological intervention to improve lifestyle self-management in patients with type 2 diabetes. Patient Educ Couns. 2001;42(3):247-256.

66. Rollnick S, Miller W, Butler CC. Motivational Interviewing in Health Care: Helping Patients Change Behavior. New York, NY: Guilford Press; 2008.

67. Garber AJ, Wahlen J, Wahl T, et al. Attainment of glycaemic goals in type 2 diabetes with once-, twice-, or thrice-daily dosing with biphasic insulin aspart 70/30 (The 1-2-3 study). Diabetes Obes Metab. 2006; $8(1): 58-66$

68. Gabriely I, Shamoon H. Hypoglycemia in diabetes: common, often unrecognized. Cleve Clin J Med. 2004;71(4):335-342.

69. Meece J. Dispelling myths and removing barriers about insulin in type 2 diabetes. Diabetes Educ. 2006;32(Suppl 1):9S-18S.

70. Arendt-Nielsen L, Egekvist H, Bjerring P. Pain following controlled cutaneous insertion of needles with different diameters. Somatosens Mot Res. 2006;23(1-2):37-43.

71. Scain SF, Friedman R, Gross JL. A structured educational program improves metabolic control in patients with type 2 diabetes: a randomized controlled trial. Diabetes Educ. 2009;35(4): 603-611.

72. Wagner EH. Chronic disease management: what will it take to improve care for chronic illness? Eff Clin Pract. 1998;1(1):2-4.
Journal of Multidisciplinary Healthcare

\section{Publish your work in this journal}

The Journal of Multidisciplinary Healthcare is an international, peerreviewed open-access journal that aims to represent and publish research in healthcare areas delivered by practitioners of different disciplines. This includes studies and reviews conducted by multidisciplinary teams as well as research which evaluates the results or conduct of such teams or

\section{Dovepress}

healthcare processes in general. The journal covers a wide range of areas and welcomes submission from practitioners at all levels, from all over the world. The manuscript management system is completely online and includes a very quick and fair peer-review system. Visit http://www.dovepress.com/testimonials.php to read real quotes from published authors. 